\title{
Pengaruh Personal Attitude, Subjective Norm, dan Perceived Behavioral Control terhadap Entrepreneurial Intention
}

\author{
Alfian Loria dan Rodhiah \\ Program Studi Manajemen Fakultas Ekonomi \& Bisnis \\ Universitas Tarumanagara \\ Email: marifan.teknik@gmail.com
}

\begin{abstract}
This study aims to determine the effect of Personal attitude, subjective norm, dan perceived behavioral control toward entrepreneurial intention. This study uses a quantitative method in which data collected by researchers uses a survey method with the "google form" platform of 80 respondents who are students of the Faculty of Economics and Business, management major at Tarumanagara University (FEB-UNTAR). Furthermore, there are three hypotheses that will be tested by calculating Likert scale data using PLS-SEM. Researcher using non-probability sampling technique with a convenience sampling approach. The data analysis method used by researchers is PLS-SEM which is calculated through the SmartPLS 3 software with bootstrapping method to measure the level of significance. The results of this study indicate that there is a significant positive effect on Personal attitude, subjective norm, dan perceived behavioral control toward entrepreneurial intention.
\end{abstract}

Keywords: Personal Attitude, Subjective Norm, Perceived Behavioral Control, and Entrepreneurial Intention

Abstrak: Penelitian ini bertujuan untuk mengetahui pengaruh Personal attitude, subjective norm, dan perceived behavioral control terhadap entrepreneurial intention. Penelitian ini menggunakan metode kuantitatif di mana data yang dikumpulkan oleh peneliti menggunakan metode survei dengan platform "google form" terhadap 80 responden yang merupakan mahasiswa Fakultas Ekonomi dan Bisnis Universitas Tarumanagara (FEB-UNTAR), Jurusan Manajemen. Selanjutnya terdapat tiga hipotesis yang akan diuji dengan cara mengkalkulasi data berskala Likert dengan menggunakan PLS-SEM. Pengambilan sampel dilakukan dengan teknik non-probability sampling dengan pendekatan convenience sampling. Metode analisis data yang digunakan oleh peneliti adalah PLS-SEM yang dikalkulasi melalui perangkat lunak SmartPLS 3 dengan metode bootstrapping untuk mengukur tingkat signifikansinya. Hasil penelitian ini menunjukkan bahwa terdapat pengaruh positif yang signifikan personal attitude, subjective norm, dan perceived behavioral control terhadap entrepreneurial intention.

Kata kunci: Sikap Pribadi, Norma Subjektif, Efikasi Diri, dan Intensi Berwirausaha

\section{LATAR BELAKANG}

Kewirausahaan adalah sebuah tindakan yang sangat penting yang harus dilaksanakan kegiatannya, di mana kegiatan ini merupakan kemampuan individu pengusaha itu sendiri untuk memperoleh peluang dengan melakukan penciptaan usaha baru, mengadopsi perubahan teknologi, dan melakukan pengembangan skala operasi secara persekutuan, mengejar dan melakukan investasi laba yang telah diperoleh (Jhingan, 1999). Kemudian menurut Untoro (2015), definisi kewirausahaan merupakan cara untuk individu dapat memanfaatkan semua 
potensi yang dimiliki untuk memperoleh sesuatu yang menghasilkan nilai tambah sehingga bermanfaat bagi dirinya sendiri maupun orang lain. Berdasarkan kedua ahli tersebut, maka disimpulkan bahwa kegiatan kewirausahaan sangat berkontribusi terhadap penciptaan lapangan pekerjaan sehingga berdampak juga terhadap kesehjahteraan masyarakat dengan mengurangi presentase/jumlah tingkat pengangguran terbuka di Indonesia.

BPS (2019) menyatakan jumlah pengangguran di Indonesia pada awal bulan Februari 2019, yakni sebanyak 6,82 juta jiwa. Jika dibandingkan dengan penduduk usia kerja Februari 2019, yakni sebanyak 196,46 juta jiwa, maka persentase pengangguran di Indonesia adalah $(6,82$ juta / 196,46 juta) X $100 \%=3,471 \%$ dari penduduk usia kerja. Angka yang telah diperoleh di atas menyatakan bahwa kesadaran /antusiasme masyarakat Indonesia dalam menjalankan kegiatan berwirausaha adalah masih kecil, maka diperlukannya faktor "Entrepreneurial Intention" agar negara Indonesia dapat terus berkembang dan tidak tertinggal oleh negara lain. KEMENKOP (Puspayoga, 2016) yang menjelaskan bahwa dengan persentase jumlah kewirausahaan di Indonesia saat ini, adalah masih terbilang sangat kecil yakni hanya $3,1 \%$ dan bila dibandingkan oleh negara lainnya khususnya negara tetangga, yakni Malaysia sendiri sudah mencapai 5\%. Hal tersebut tentu saja rasio kewirausahaan di Indonesia masih 1,9\% di bawah Malaysia, apalagi dibandingkan dengan negara lainnya seperti Singapura 7\%, Tiongkok 10\%, Jepang 11\%, dan Amerika Serikat 12\%.

Adapun terdapat sebuah teori yang dibuat dan sekaligus dikembangkan oleh Ajzen (1991) yakni "Theory of Planned Behavior (TPB)". Menurut Miller dkk. (2009), pada teori tersebut terdapat isi bahwa terdapat tiga faktor yang sangat efektif untuk mengukur entrepreneurial intention seorang individu, yakni: personal attitude, subjective norm, dan perceived behavioral control.

\section{KAJIAN TEORI}

Teori yang digunakan untuk mengukur entrepreneurial intention individu pada penelitian ini adalah "Theory of Planned Behavior (TPB)" yang merupakan sebuah teori yang dikembangkan oleh (Ajzen, 1991 dalam Jogiyanto 2007). Munculnya teori ini adalah pengembangan dari teori sebelumnya, yakni Theory of Reasoned Action (TRA) yang dibuat dan dikembangkan oleh (Ajzen dan Fishbein, 1975 dalam Jogiyanto, 2007). Pengembangan tersebut dilakukan dengan cara menambahkan konstruk yang belum ada pada TRA, yakni perceived behavioral control. Menurut Hsu dan Chiu (2002) konstruk perceived behavioral control ditambahkan dengan tujuan untuk mengontrol sebuah perilaku yang dilakukan individu berdasarkan kekurangan dan keterbatasan dari adanya kekurangan sumber daya yang dipakai untuk melakukan perilakunya. Theory of Planned Behavior memiliki tiga komponen utama yang menjelaskan bahwa intention/niat seorang individu untuk melakukan perilaku tertentu ditentukan oleh: personal attitude pada individu tersebut, subjective norm yang berasal dari lingkungan eksternal (orang lain) maupun internal (keluarga, kerabat, saudara, dll), dan perceived behavioral control yang berasal dari sisi internal individu tersebut (Ajzen, 1991 dalam Zewudu dan Alamnie 2017).

Personal attitude. adalah kecenderungan evaluasi pada individu untuk mengeksekusi respon dalam pengambilan keputusan untuk menyukai ataupun tidak menyukai terhadap hal-hal yang berkaitan dengan kegiatan kewirausahaan, di mana jika kegiatan wirausaha disukai maka mereka akan melibatkan diri mereka untuk melakukan penciptaan usaha dan sebaliknya (Hunt dan Osborn, 2002; Zewudu dan Alamnie, 2017; Usman dan Yennita, 2019; Roy, Akhtar, dan Das, 2017).

Subjective norm. adalah tindakan atau perilaku tertentu oleh individu yang muncul akibat adanya tekanan sosial di mana pengaruh pada lingkungan sosial berdampak pada keinginan 
individu untuk melakukan suatu hal atau tidak berdasarkan keyakinannya bahwa keinginan tersebut dilakukan jika diterima oleh pihak lain (Zewudu dan Alamnie, 2017; Usman dan Yennita, 2019; Roy, Akhtar dan Das, 2017; Linan dan Santos, 2010)

Perceived behavioral control. Adalah penilaian pada persepsi diri individu berdasarkan kepercayaan yang dimilikinya bahwa mereka mampu untuk melakukan hal tertentu di mana hal ini mempengaruhi keputusannya untuk berprilaku/terlibat dalam melaksanakan suatu kegiatan seperti kewirausahaan, bermodalkan pengetahuan, sumber daya, dan dengan cara memanfaatkan peluang yang ada (Linan dan Santos, 2010; Usman dan Yennita, 2019; Kolvereid dan Isaksen, 2006; Zewudu dan Alamnie, 2017; Sun, Tung dan Lo, 2016).

Entrepreneurial intention. adalah kecenderungan individu berdasarkan proses berpikir individu untuk memfokuskan diri pada pengalaman, perhatian, dan berperilaku untuk terlibat dalam kegiatan kewirausahaan yang mengacu pada hal seperti membuat bisnis baru, menetapkan target untuk usaha yang dibentuk, dan bertindak sebagai pengusaha (Zewudu dan Alamnie, 2017; Linan dan Santos, 2010; Usman dan Yennita, 2019; Douglas dan Shepherd, 2002).

Kaitan Personal Attitude dengan Entrepreneurial Intention. Penelitian Usman dan Yennita (2019) terhadap 122 responden dari 25 universitas terpilih menyatakan bahwa adanya pengaruh yang kuat antara personal attitude mahasiswa kewirausahaan terhadap entrepreneurial intention di mana menurutnya ada beberapa penelitian empiris juga membuktikan bahwa adanya hubungan positif antara entrepreneurial intention dengan decision-making process yang membutuhkan beberapa soft skill, di mana skill tersebut dibutuhkan untuk mengembangkan personal attitude mereka untuk mengambil tindakan entrepreneursip. Penelitian Zewudu dan Alamnie (2017) menjelaskan bahwa keyakinan dasar individu, dapat menjelaskan hubungan personal attitude dengan entrepreneurial intention yang ditunjukkan dari keyakinan dan attitude individu itu sendiri dalam hal mengeksekusi perilaku tertentu yang mengkonfirmasikan bahwa mereka akan melakukan tindakan-tindakan terkait kegiatan dalam membuka usahanya. penelitian Emnet dan Chalchissa (2013) yang meneliti 210 mahasiswa/I dari Universitas Jimma, Addis Abba, Adama, dan Haramaya menemukan bahwa personal attitude mahasiswa mengenai sebuah pekerjaan, $40 \%$ dari mereka menjawab bahwa mereka lebih memilih untuk menjadi wirausahawan daripada bekerja di perusahaan orang lain. Penelitian Guerrero dkk. (2006) terhadap 719 mahasiswa yang bertajuk "mahasiswa yang mengambil konsentrasi kewirausahaan" dan yang "tidak mengambil konsentrasi kewirausahaan" serta "mahasiswa yang mengambil jurusan teknik" pada tahun akademik 2004-2005 menemukan bahwa personal attitude mahasiswa pada entrepreneurial intention memiliki kaitan yang kuat.

Kaitan Subjective Norm dengan Entrepreneurial Intention. Usman dan Yennita (2019) pada penelitiannya terhadap 122 responden dari 25 universitas terpilih di Turki menyatakan bahwa subjective norm berperan penting dalam meningkatkan entrepreneurial intention, yang ditunjukkan dengan semakin banyak pihak-pihak lain di lingkungan sekitar individu yang mendukung dan mendorong untuk invididu tersebut melakukan perilaku kewirausahaan maka akan meningkatkan entrepreneurial intention mereka untuk memulai usaha yang akan dibentuknya. Menurut penelitian Roy, Akhtar dan Das (2017) terhadap 476 lulusan muda di bidang Science \& Technology di India menemukan bahwa adanya hubungan positif dan signifikan pada subjective norm dengan entrepreneurial intention. Penelitian Zewudu dan Alamnie (2017) juga menyatakan bahwa peran subjective norm hadir dengan cara individu yang merasa bahwa jika pihak lain akan menerima ide/keputusan yang dibuatnya untuk membentuk usaha baru maka individu tersebut akan memiliki entrepreneurial intention yang 
kuat untuk melakukannya maka dari hasil penelitiannya juga ditemukan adanya kaitan yang kuat antara subjective norm terhadap entrepreneurial intention.

Kaitan Perceived Behavioral Control dengan Entrepreneurial Intention. Penelitian Linan dan Santos (2010) menjelaskan bahwa perceived behavioral control adalah persepsi individu mengenai kemampuan mereka untuk bisa melakukan aktivitas kewirausahaan di mana hal tersebut akan meningkatkan entrepreneurial intention individu dalam menjalankan kegiatan kewirausahaan. Menurut penelitian Dugassa (2012) di Ethiopia pada Universitas Jumma dan Addis Abba terhadap 236 mahasiswa tingkat akhir manajemen dan teknik menyatakan bahwa perceived behavioral control merupakan determinan/penentu positif untuk meningkatkan entrepreneurial intention. Kemudian dalam penelitian yang dilakukan oleh Usman dan Yennita (2019) pada penelitiannya terhadap 122 responden dari 25 universitas terpilih di Turki menyatakan bahwa terdapat kaitan yang kuat antara perceived behavioral control terhadap entrepreneurial intention seseorang, di mana menurutnya bahwa sebuah pertimbangan individu untuk berkecimpung dalam dunia usaha (entrepreneurial intention) adalah ditentukan dari seberapa besarnya individu tersebut merasa dirinya sanggup dan mampu untuk mendirikan usaha (perceived behavioral control) yang didasari dari pengalaman yang didapat selama hidupnya, pelajaran dan didikan yang diperolehnya, dan peluang yang dirasakan ketika memutuskan untuk menjalakan usaha.

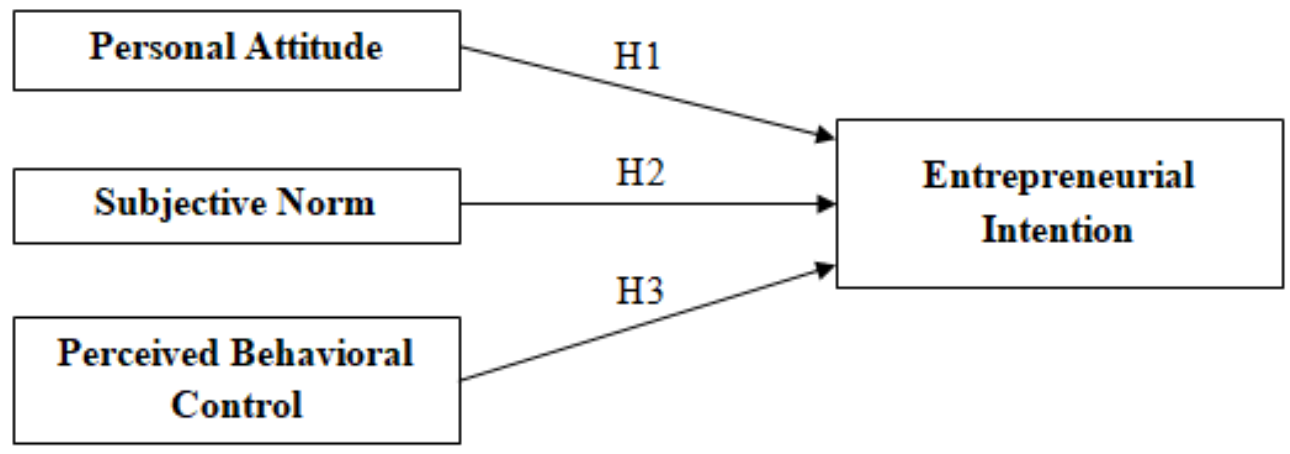

Gambar 1. Kerangka pemikiran

Berdasarkan pada latar belakang penelitian hingga sampai pada kerangka pemikiran yang telah dirumuskan oleh peneliti, maka adapun hipotesis yang dirumuskan oleh peneliti adalah sebagai berikut:

H1 : $\quad$ Terdapat pengaruh positif dan signifikan personal attitude terhadap entrepreneurial intention pada mahasiswa S1 Manajemen UNTAR.

$\mathrm{H} 2$ : $\quad$ Terdapat pengaruh positif dan signifikan subjective norm terhadap entrepreneurial intention pada mahasiswa S1 Manajemen UNTAR.

H3 : Terdapat pengaruh positif dan signifikan perceived behavioral control terhadap entrepreneurial intention pada mahasiswa S1 Manajemen UNTAR.

\section{METODOLOGI}

Penelitian ini menggunakan desain penelitian yang bersifat konklusif, di mana penelitian konklusif menurut Malhotra (2010:104) adalah "Riset yang dibuat untuk membantu peneliti dalam mengevaluasi, menentukan bahkan memilih suatu rangkaian tindakan yang harus diambil pada situasi tertentu". Malhotra (2010:106) deskriptif merupakan "Suatu jenis riset konklusif yang memiliki tujuan utamanya yakni mendeskripsikan/menguraikan sesuatu dan selalu digunakan untuk menjelaskan karakteristik ataupun fungsi pasar". Selanjutnya, 
menurut Aritonang (2007:6) menjelaskan bahwa penelitian deskriptif merupakan sebuah penelitian yang tidak melakukan manipulasi pada variabelnya atau dengan kata lain yakni situasi yang diteliti tidak mendapatkan perlakuan tertentu.

Menurut Sugiyono (2011:80) menyatakan bahwa "Populasi merupakan wilayah generalisasi yang terdiri dari: subjek atau objek yang memiliki kualitas dan karakteristik tertentu yang telah ditetapkan oleh peneliti untuk dikaji/dipelajari dan kemudian dilakukannya pembahasan serta membuat kesimpulan. Pada penelitian ini, populasinya adalah seluruh mahasiswa Fakultas Ekonomi dan Bisnis, Universitas Tarumanagara. Teknik pemilihan sampel yang digunakan pada penelitian ini adalah "non-probability sampling". Margono (2004) menjelaskan bahwa teknik penmilihan sampel merupakan cara penulis/peneliti mengambil sampel hingga jumlahnya sesuai/mencukupi dengan ukuran sampel yang telah ditetapkan oleh peneliti. Non-probability sampling memiliki beberapa pendekatan tetapi yang digunakan dalam penelitian ini adalah convenience sampling di mana merupakan sebuah teknik pengambilan sampel yang dipilih dengan alasan kemudahan pihak peneliti dalam mengumpulkan data, yang dilakukan dengan pengambilan sampel pada orangorang yang peneliti anggap sesuai, dan dengan mudah didapatkan oleh peneliti (Aritonang, 2007:95). Ukuran sampel pada penelitian ini menggunakan 80 responden yang terpilih dan terkriteria sebagai responden.

Hair dkk. (2011) menyatakan bahwa uji pengukuran pada penelitian dilakukan dengan cara melihat dan menganalisis validitas dan reliabilitas dari model penelitian yang telah dibentuk secara keseluruhan. Pengukuran validitas dalam penelitian ini dapat dilakukan dengan cara melihat besarnya nilai yang dihasilkan oleh convergent validity dan discriminant validity. Pengujian validitas konvergen ditinjau dari nilai yang dihasilkan oleh outer loadings dan Average Variance Extracted (AVE). Pada nilai outer loadings menunjukkan derajat kesesuaian pada indikator dalam mencerminkan variabel konstruk. Kemudian adapun rule of thumb yang harus terpenuhi agar data yang dihasilkan layak dinyatakan valid secara konvergen, yakni: nilai outer loadings wajib di atas 0,7 (Chin, 1998) tetapi untuk penelitian tahap awal nilai di atas 0,5-0,7 masih dapat diterima (Ghozali, 2015). Selanjutnya, pada nilai AVE yang harus dihasilkan adalah wajib di atas 0,5 (Hensler dkk., 2009). Selanjutnya pengujian validitas diskriminan dilakukan dengan melihat nilai yang dihasilkan ol eh FornellLarcker Criterion dan Cross Loadings. Menurut Garson (2016), sebagai syarat terpenuhinya validitas diskriminan, Fornell-Larcker Criterion harus memenuhi syarat, yakni (Akar kuadrat AVE > korelasi antar variabel laten), kemudian Cross Loadings harus memenuhi syarat, yakni (Nilai indikator terhadap variabel sendiri > nilai indikator terhadap variabel lain). Analisis reliabilitas dilakukan dengan menggunakan metode PLS-SEM dengan bantuan software SmartPLS 3. Untuk mengetahui apakah suatu data yang telah dikumpulkan bersifat reliabel maka ditinjau dari nilai yang dihasilkan oleh composite reliability dan cronbach's alpha. Malhotra (2009) menyatakan bahwa nilai minimal/rule of thumb yang harus terpenuhi agar suatu data dapat dinyatakan reliabel adalah menghasilkan nilai 0,6 pada composite reliability dan cronbach's alpha. Apabila semua variabel yang digunakan dalam penelitian telah mencapai nilai di atas 0,6 maka dapat ditarik kesimpulan bahwa data yang dipakai dalam penelitian sudah bersifat reliabel/andal/konsisten dalam mengukur suatu fenomena.

Variabel dan jumlah pernyataan yang digunakan dan yang akan diolah datanya dalam penelitian ini, tersaji dalam tabel 1 berikut ini:

Tabel 1. Konstruk penelitian

\begin{tabular}{|l|l|c|c|}
\hline No & \multicolumn{1}{|c|}{ Variabel } & Pernyataan & Sumber \\
\hline 1 & Personal Attitude & 5 & \multirow{2}{*}{ Usman dan Yennita (2019) } \\
\hline 2 & Subjective Norm & 3 & \\
\hline 3 & Perceived Behavioral Control & 5 & \\
\hline
\end{tabular}




\section{HASIL UJI STATISTIK}

\section{Uji validitas}

Pada hasil validitas didapatkan semua angka pada setiap pernyataan $>0,5$ pada nilai outer loadings untuk setiap pernyataannya, dan didapatkan semua angka $>0,5$ pada nilai Average Variance Extracted / AVE maka semua pernyataan dan variabel yang digunakan sudah valid. Hasil kalkulasi Fornell-Larcker Criterion yang menghasilkan (nilai akar kuadrat AVE > daripada korelasi antar variabel latennya). Nilai indikator terhadap variabel sendiri lebih besar dari pada nilai indikator terhadap variabel lain maka disimpulkan bahwa berdasarkan pengujian validitas diskriminan, semua variabel dan indikator yang digunakan dalam penelitian ini adalah valid yang beracuan pada nilai cross loadings.

\section{Uji reliabilitas}

Pada hasil reliabilitas, maka berdasarkan hasil yang dikalkulasi oleh program SmartPLS 3, didapatkan semua angka pada nilai Cronbach's Alpha untuk setiap pernyataannya adalah > 0,6 dan pada nilai Composite Reliability didapatkan semua angka untuk setiap pernyataannya adalah > 0,6. Maka pernyataan yang digunakan dalam penelitian ini sudah reliabel berdasarkan kedua nilai reliabilitas, yakni Cronbach's Alpha dan Composite Reliability.

\section{Pengujian konstruk penelitian}

Nilai R-square $\left(\mathrm{R}^{2}\right)$ yang dihasilkan sebesar 0,670 (bersifat moderat/sedang) pada variabel entrepreneurial intention. Memiliki arti, variabel personal attitude, subjective norm, dan perceived behavioral control merupakan prediktor yang sedang/moderat dalam mempengaruhi entrepreneurial intention. Kemudian nilai koefisien determinasi (Kd) yang dihasilkan adalah $0,670 \times 100 \%=67 \%$, yang artinya bahwa sebesar $67 \%$ variabel entrepreneurial intention dipengaruhi oleh variabel personal attitude, subjective norm, dan perceived behavioral control dan kemudian sisanya $(100 \%-67 \%)=33 \%$ variabel entrepreneurial intention dipengaruhi oleh variabel lain. Uji Q-Square menghasilkan nilai 0,400 artinya konstruk penelitian memiliki predictive relevance yang baik. Uji GoF yang dihasilkan adalah sebesar 0,6422 yang artinya tingkat kesesuaian atau kelayakan pada model penelitian ini besar.

Tabel 2. Hasil Pengujian Hipotesis

\begin{tabular}{|c|c|c|c|c|c|}
\hline Kode & Hipotesis & $\begin{array}{c}\text { Original } \\
\text { Sample }\end{array}$ & $\begin{array}{c}\text { T } \\
\text { statistics }\end{array}$ & P values & Kesimpulan \\
\hline H1 & $\begin{array}{c}\text { Personal Attitude } \rightarrow \\
\text { Entrepreneurial Intention }\end{array}$ & 0,231 & 1,919 & 0,028 & Tidak ditolak \\
\hline $\mathrm{H} 2$ & $\begin{array}{c}\text { Subjective Norm } \rightarrow \\
\text { Entrepreneurial Intention }\end{array}$ & 0,289 & 2.370 & 0,009 & Tidak ditolak \\
\hline $\mathrm{H} 3$ & $\begin{array}{c}\text { Perceived Behavioral } \\
\text { Control } \rightarrow \text { Entrepreneurial } \\
\text { Intention }\end{array}$ & 0,424 & 2,863 & 0,002 & Tidak ditolak \\
\hline
\end{tabular}

\section{DISKUSI}

Hasil uji hipotesis menunjukkan bahwa H1: Terdapat pengaruh positif dan signifikan personal attitude terhadap entrepreneurial intention pada mahasiswa S1 Manajemen UNTAR adalah tidak ditolak secara statistik. Hasil penelitian ini sejalan dengan penelitian Usman dan Yennita (2019) yang meneliti 122 orang dari 25 universitas terpilih yang menyatakan pengaruh personal attitude terhadap entrepreneurial intention bersifat kuat dan positif. Kemudian sejalan dengan hasil penelitian yang dilakukan Emnet dan Chalchissa (2013) yang 
meneliti 210 mahasiswa/I dari Universitas Jimma, Addis Abba, Adama, dan Haramaya menemukan bahwa personal attitude mahasiswa mengenai sebuah pekerjaan, $40 \%$ dari mereka menjawab bahwa mereka lebih memilih untuk menjadi wirausahawan daripada bekerja di perusahaan orang lain. Adapun studi banding oleh penelitian Guerrero dkk. (2006) terhadap 719 mahasiswa yang bertajuk "mahasiswa yang mengambil konsentrasi kewirausahaan" dan yang "tidak mengambil konsentrasi kewirausahaan" serta "mahasiswa yang mengambil jurusan teknik" pada tahun akademik 2004-2005 menemukan bahwa personal attitude mahasiswa pada entrepreneurial intention memiliki kaitan yang kuat karena menurut studinya menjelaskan bahwa faktor untuk seorang individu menghasilkan entrepreneurial intention sangat bergantung pada personal attitude mereka, di mana dengan adanya personal attitude maka individu dapat menentukan perilaku apa yang harus dilakukan untuk memulai bisnis yang akan dibentuk. Selanjutnya, studi yang dilakukan Zewudu dan Alamnie (2017) yang menjelaskan bahwa keyakinan dasar individu, dapat menjelaskan hubungan personal attitude dengan entrepreneurial intention yang ditunjukkan dari keyakinan dan attitude individu itu sendiri dalam hal mengeksekusi perilaku tertentu yang mengkonfirmasikan bahwa mereka akan melakukan tindakan-tindakan terkait kegiatan dalam membuka usahanya. Hal ini disimpulkan bahwa secara teoritis mendukung hasil penelitian bahwa personal attitude berpengaruh positif terhadap entrepreneurial intention.

H2: Terdapat pengaruh positif dan signifikan subjective norm terhadap entrepreneurial intention pada mahasiswa S1 Manajemen UNTAR adalah tidak ditolak secara statistik. Hasil penelitian ini sejalan dengan penelitian Usman dan Yennita (2019) yang meneliti 122 orang dari 25 universitas terpilih yang menyatakan subjective norm berperan penting dalam meningkatkan entrepreneurial intention, yang ditunjukkan dengan semakin banyak pihakpihak lain di lingkungan sekitar individu yang mendukung dan mendorong untuk invididu tersebut melakukan perilaku kewirausahaan maka akan meningkatkan entrepreneurial intention mereka untuk memulai usaha yang akan dibentuknya. pengaruh personal attitude terhadap entrepreneurial intention bersifat kuat dan positif. Kemudian sejalan dengan penelitian Roy, Akhtar dan Das (2017) terhadap 476 lulusan muda di bidang Science \& Technology di India menemukan bahwa adanya hubungan positif dan signifikan pada subjective norm dengan entrepreneurial intention yang mana pada penelitian tersebut juga menjelaskan bahwa dalam bidang science \& technology ada banyak pengembanganpengembangan yang dilakukan dalam hal menciptakan suatu teknologi baru untuk dapat menyokong penemuan ilmu-ilmu \& senyawa baru di bidang sains, maka dari hal itu seseorang yang mengambil bidang tersebut akan terus didorong untuk menjadi pengusaha di lingkungan tempat mereka berkuliah maka (subjective norm) yang mana akan mengaktifkan entrepreneurial intention mereka. Selanjutnya penelitian Zewudu dan Alamnie (2017) juga menyatakan bahwa peran subjective norm hadir dengan cara individu yang merasa bahwa jika pihak lain akan menerima ide/keputusan yang dibuatnya untuk membentuk usaha baru maka individu tersebut akan memiliki entrepreneurial intention yang kuat untuk melakukannya maka dari hasil penelitiannya juga ditemukan adanya kaitan yang kuat antara subjective norm terhadap entrepreneurial intention. Hal ini disimpulkan bahwa secara teoritis mendukung hasil penelitian bahwa subjective norm berpengaruh positif terhadap entrepreneurial intention.

H3: Terdapat pengaruh positif dan signifikan perceived behavioral control terhadap entrepreneurial intention pada mahasiswa S1 Manajemen UNTAR adalah tidak ditolak secara statistik. Hasil penelitian ini sejalan dengan penelitian Usman dan Yennita (2019) pada penelitiannya terhadap 122 responden dari 25 universitas terpilih di Turki menyatakan bahwa terdapat kaitan yang kuat antara perceived behavioral control terhadap entrepreneurial intention seseorang, di mana menurutnya bahwa sebuah pertimbangan individu untuk berkecimpung dalam dunia usaha (entrepreneurial intention) adalah ditentukan dari seberapa 
besarnya individu tersebut merasa dirinya sanggup dan mampu untuk mendirikan usaha (perceived behavioral control) yang didasari dari pengalaman yang didapat selama hidupnya, pelajaran dan didikan yang diperolehnya, dan peluang yang dirasakan ketika memutuskan untuk menjalakan usaha. Kemudian sejalan dengan hasil penelitian Linan dan Santos (2010) dan penelitian Dugassa (2012) di Ethiopia pada Universitas Jumma dan Addis Abba terhadap 236 mahasiswa tingkat akhir manajemen dan teknik menyatakan bahwa perceived behavioral control merupakan determinan/penentu positif untuk meningkatkan entrepreneurial intention. Hal tersebut juga dijelaskan bahwa dengan adanya kepercayaan diri individu terhadap kemampuan yang dirasa dapat melakukan pendirian usaha sendiri maka individu tersebut pasti akan cenderung berkecimpung untuk melibatkan diri pada berbagai aktivitas kewirausahaan. Hal ini disimpulkan bahwa secara teoritis mendukung hasil penelitian bahwa perceived behavioral control berpengaruh positif terhadap entrepreneurial intention.

\section{Penutup}

Personal attitude, subjective norm, dan perceived behavioral control secara positif dan signifikan mempengaruhi entrepreneurial intention dengan tingkat keyakinan $95 \%$ dan didukung secara teori. Keterbatasan dalam penelitian ini adalah pada ukuran sampel yang relatif kecil (80 responden), wilayah populasi penelitian masih sempit hanya di UNTAR FEB - Manajemen, selajutnya penelitian ini hanya menggunakan 3 variabel independen saja untuk mempengaruhi entrepreneurial intention. Peneliti menyarankan untuk peneliti selanjutnya agar mengembangkan penelitian ini dalam berbagai konteks, kemudian menambah variabelvariabel baru yang mempengaruhi entrepreneurial intention serta menambah jumlah sampel.

\section{Daftar Pustaka}

Ajzen, I. 1991. The theory of planned behavior. Organizational Behavior and Human Decision Processes, 50: 179-211.

Aritonang. R. 2007. Riset pemasaran Teori \& praktik. Bogor: Ghalia Indonesia.

Berita Resmi Statistik. 2019. Keadaan ketenagakerjaan Indonesia Februari 2019. Berita resmi statistik : No. 41/05/Th.XXII, 6 Mei 2019. Diakses pada (Mei 12, 2019) dari: BRSbrsInd-20190508080909_rev.

Chin, W.W. 1998. The partial least squares approach for structural equation modeling. in G. A. Marcoulides (Ed.). Modern methods for business research. London: Lawrence Erlbaum Associates.

Douglas, E., \& Shepherd, D. 2002. Self-employment as a Career Choice: Attitudes, Entrepreneurial Intentions, and Utility Maximization: Entrepreneurship Theory and Practice, 26(3) 81-90.

Dugassa, Tesema. 2012. Impact of entrepreneurship education on entrepreneurial intentions of business and engineering students in Ethiopia: African Journal of Economic and Management Studies, 3(2), 258 - 277.

Garson, G. D. 2016. Partial Least Squares: Regression \& Structural Equation Models. G. David Garson and Statistical Associates Publishing.

Ghozali, Imam. 2015. Aplikasi Analisis Multivariate dengan Program IBM SPSS 23. Semarang : Badan Penerbit Universitas Diponegoro.

Guerrero, M., Rialp, J., dan Urbano, D. 2006. The impact of desirability and feasibility on entrepreneurial intentions: A structural equation model: International Entrepreneurship and Management Journal, 4, 35-50.

Hair, J. F., Ringle, C. M., \& Sarstedt, M. 2011. PLS-SEM: Indeed a silver bullet.

Henseler, J. Ringle, C.M. \& Sinkovicks, R.R. 2009. The use of partial least square modeling in international marketing. New Challenges to International Marketing Advances in International Marketing, 20, 277-319. 
Hsu, M. H. And Chiu, C. M. 2002. Predicting Electronic Service Continuance with a Decomposed Theory of Planned Behavior. Behavior dan Information Technology.

Jhingan, M.L.1999. Ekonomi Pembangunan dan Perencanaan. Jakarta: Penerbit Rajawali Pers.

Jogiyanto, Hartono. 2007. Model Kesuksesan Sistem Teknologi Informasi. Yogyakarta: Andi.

Kolvereid, L. dan Isaksen, E. 2006. New business start-up and subsequent entry into selfemployment. Journal of Business Venturing, 21(6), 866-885. Retrieved from: https://doi.org/10.1016/j.jbusvent.2005. 06.008.

Liñán, F dan Santos, F. 2010. Gender differences in entrepreneurial intentions: An international comparison: Working paper, Sevilla, Spain.

Malhotra, Naresh K. 2009. Riset pemasaran pendekatan terapan. jilid 1. Jakarta: PT Index. 2010. Marketing Research An Applied Orientation. Sixth Edition. New Jersey: Pearson.

Margono. 2004. Metodologi Penelitian Pendidikan. Jakarta: PT Rineka Cipta.

Miller, B. K. dkk. 2009. Predictors of entrepreneurial intentions: A quasi-experiment comparing students enrolled in introductory management and entrepreneurship classes. Journal of Business and Entrepreneurship, 21(2), 39-62. https://doi.org/10.1017/CBO9781107415324.004.

Roy, R., Akhtar, F., \& Das, N. 2017. Entrepreneurial intention among science \& technology students in india: Extending the theory of planned behavior. International Entrepreneurship and Management Journal, 13(4), 1013-1041. doi:http://dx.doi.org/10.1007/s11365-017-0434-y

Schermerhorn, John D., James G Hunt, Richard N Osborn. 2002. Organizational Behavior. New York: John Willey and Son Inc.

Sugiyono. 2011. Metode Penelitian Kuantitatif Kualitatif, dan R\&D. Cetakan ke- 14. Bandung: Alfabeta.

Sun, H., Lo, C. Tung., Liang, B., \& Wong, Y. L. B. 2017. The impact of entrepreneurial education on entrepreneurial intention of engineering students in hong kong. Management Decision, 55(7), 1371-1393. Retrieved from https://search.proquest.com/docview/1929855111? accountid=45753.

Untoro, Joko. 2015. Ekonomi. Jakarta: Kawah Media.

Usman, B. dan Yennita. 2019. Understanding the entrepreneurial intention among international students in turkey. Journal of Global Entrepreneurship Research, 9(1), 1. Retrieved from: http://dx.doi.org/10.1186/s40497-018-0136-0.

Zewudu, W., M.B.A., \& Alamnie, M. 2017. Determinants of entrepreneurial intention of graduating students at Bahirdar university: An application of theory of planned behavior. Arabian Journal of Business and Management Review (Oman Chapter), 7(1), 31-50. Retrieved from doi:http://dx.doi.org/10.12816/0041746. 